\title{
Bärbel Inhelder Procura Falsear o Modelo Piagetiano; antes da Teoria de Popper (?)
}

\author{
Zdia Ramozzi-Chiarottino ${ }^{1}$ \\ UniversidadedeSão Paulo
}

\begin{abstract}
Resumo
Neste artigo, buscamos trazer à luz um dos aspectos desconhecidos do trabalho de uma das maiores psicólogas do século XX: Bärbel Inhelder. Até hoje apenas reconhecida como a maior colaboradora de Piaget, tem sido ignorada como a criadora de um método científico capaz de refutar (em vez de confirmar) um modelo hipotético-dedutivo na área da Psicologia, antes ou simultaneamente à idéia de Popper. Partiu do modelo matemático de Piaget, o agrupamento, e realizou seu estudo com oligofrênicos. Demonstra que quanto mais severo o comprometimento cerebral menor a presença de esboços dos agrupamentos subjacentes às ações e ao discurso das crianças e vice-versa.

Palavras-chave: Falseabilidade; modelo piagetiano; funcionamento cerebral.
\end{abstract}

Bärbel Inhelder Tries to Falsify the Piagetian Model; Prior to Popper's Theory (?)

\begin{abstract}
In this article we search to bring to light one of the unknown aspects of the work of one of the 20th century's greatest psychologists: Bärbel Inhelder. Thus far recognized only as the most remarkable Piaget collaborators, she has been ignored as the creator of a scientific method apt to refute (instead of corroborating) a hypothetical-deductive model in the realm of Psychology, prior or simultaneously to Popper's idea. Based on Piaget's mathematical model, the grouping, she did her study on oligophrenics. She demonstrates that the more severe the brain lesions, the lesser the presence of the groupings' structural sketches underlying the children's actions and speech, and vice-versa.

Keywords: Falsification; the Piagetian model; cerebral functioning.
\end{abstract}

A Teoria do Conhecimento de Piaget, esboçada desde a adolescência toma-se pouco a pouco uma teoria científica com a construção de um Modelo hipotético-dedutivo. Num primeiro momento diz Piaget (1959) que encara a Lógica como um modelo descritivo daquilo que observara; diz ele: "as operações lógicas cujo simbolismo eu estudava em Couturat, forneciam-me exatamente o modelo do qual eu precisava para compreender as dificuldades dos meus garotos" (p. 60). Num segundo momento ele irá criar seu próprio modelo explicativo do raciocínio humano, das funções cognitivas, ou seja, o modelo do funcionamento das estruturas mentais orgânicas específicas para 0 ato de conhecer. Que modelo é esse? A lógica operatória. A esse propósito Piaget (1952) escreve: "Sem ser uma Lógica, a lógica operatória é uma teoria algébrica das estruturas em função das quais, o pensamento real impõe a si próprio, uma lógica, isomorfa à Lógica de Classes e Relações" (p. 81). Em Les modêesabstraits dansl'explication en psychologie, ele escreve:

As operações são ações interiorizadas que prolongam as estruturas sensório-motoras e refletem as formas (de funcionamento) do organismo, é o que tenho afirmado

\footnotetext{
${ }^{1}$ Endereço para correspondência: Al. Ministro Rocha Azevedo, 464/102, 01410-000, São Paulo, SP. Fone/ Fax: (11) 30836883, E-mail: zramozzi@yahoo.com.br
}

incessantementeeno quecreio atéhoje... Minha idéia central, (inspirada pelas relações entre o nível sensório-motor e 0 nível operatório, ondeo segundo prolonga o primeiro após toda uma fase de reelaboração sobre um novo plano, o da representação) era e continua a ser, a de que o desenvolvimento não é retilíneo mas que cada conjunto de construções deve ser reconstruído sobre o patamar seguinte antes de ser prolongado: nessa perspectiva, não se trata de uma simples volta à "préformação" mas sim de se supor as estruturas operatórias como virtualmente contidas no funcionamento cerebral. Eu imaginava pois, circuitos neuronais associados, necessariamente, sob as formas de grupo ou de "rede" (no sentido matemático). Aliás, depois do que os trabalhos de Mc Culloch, Ashby, etc , mostraram, não há aí nada de quimérico . (Piaget, 1959, p. 10)

Essas hipóteses, mesmo não sendo quiméricas, não poderiam ser comprovadas ou observadas diretamente, donde a necessidade da criação de um modelo abstrato, hipotético, mas que fosse passível de ser verificado na experiência, já que poderia ter conseqüências para a vida das pessoas. A palavra Modelo é empregada, aqui, exatamente no sentido da Física, ou seja, um modelo análogo àquele da estrutura do átomo, que foi criado para explicar os efeitos observáveis de um objeto do conhecimento não diretamente observável. $O$ sentido de "verificável na experiência" é o seguinte: os modelos das 
Ciências da Empiria, aquelas que têm um referente no mundo, devem ser passíveis de verificação uma vez que servirão, cedo ou tarde, para o cientista atuar nesse mundo. Que mundo? O seu, o nosso, o "humilde" mundo limitado a três dimensões...

Bärbel Inhelder desempenha um papel muito significativo na constituição do Modelo Piagetiano, "lógica operatória", enquanto modelo verdadeiramentecientífico, na medida em que descobre uma estratégia, um método, para falsear esse modelo que se traduz, formalmente, nas estruturas do "agrupamento" e do grupo INRC. Bärbel dedicar-seá apenas ao agrupamento (essa estrutura matemática, modelo teórico, abstrato, do funcionamento das estruturas mentais, explicaria a lógica operatória subjacente ao comportamento, discurso e raciocínio do ser humano, até, em média, a idade de 11-12 anos, daí para frente a estrutura éa do grupo INRC). Bärbel realizou essa empreitada difícil e jamais vista, até então, fora do âmbito dasCiências Exatas em Lediagnostic du raisonnement chez les débiles mentaux, publicado em 1943. Tarefa nada trivial, pelo fato de que esse modelo refere-se sempre às condições necessárias e não às suficientes, para que o ser humano seja capaz de raciocinar.

O agrupamento, já dissemos, é uma estrutura matemática que contém o conjunto das classes e relações que espelham, segundo Piaget, o funcionamento cerebral enquanto específico para o ato de conhecer e que estão subjacentes às ações das crianças quando estas brincam organizando seu mundo segundo seus próprios critérios; estando também subjacentes aos seus discursos que dublam essas ações quando estão a explicar esse mundo. Essa estrutura, agrupamento, que se encontra entre os "monóides" e os "grupos", no sentido matemático, e que é parte do modelo piagetiano relativo ao funcionamento das estruturas mentais, corresponderia a uma construção endógena virtualmente contida no funcionamento cerebral específico para o ato deconhecer o mundo. Daí o fato da criança já revelar em suas primeiras ações e, depois, em seu discurso uma lógica isomorfa à Lógica de Classes e Relações, ainda que ligada aos objetos do mundo concreto e ainda sem alcançar a mobilidade do grupo INRC. Em suma, o agrupamento reflete um início de poder dedutivo ainda que não liberado de manipulações concretas. Esse poder dedutivo nada mais é que um aspecto fundamental do funcionamento cerebral, ou seja, o funcionamento das estruturas mentais (lembremos: orgânicas e específicas para 0 ato de conhecer) que, por hipótese, é isomorfo à Lógica de Classes e Relações. Donde aparecerem desde a mais tenra idade no comportamento da criança. As classificações empíricas (dassements), por exemplo, por cor, forma e tamanho e as seriações ou ordenações, que prefiguram as futuras Classes e Relações, constituem-se na baseena condição necessária para qualquer tipo deraciocínio que o ser humano possa realizar onde quer que ele viva.

Por que Inhelder $(1943 / 1963)$ teria imaginado que um trabalho com os deficientes mentais, com lesão cerebral bem definida (oligofrênicos), poderia verificar o modelo piagetiano? Ela queria demonstrar aquilo que Piaget chamou de sua idéia central e que supunha, como dissemos, as estruturas operatórias já virtualmente contidas no funcionamento cerebral enquanto circuitos neuronais tomando necessariamente a forma de grupo ou rede (no sentido matemático).

Se Piaget fala sempre de condições necessárias, a forma sempre presente é a do condicional: se $p$ então $q$ (p sendo a condição suficiente e q a condição necessária). Se eu tenho p necessariamente eu tenho q.

Inhelder (1943/1963) dá à idéia de Piaget a forma adequada: se existem agrupamentos de classes e relações subjacentes à ação e ao discurso então: existem estruturas operatórias sob a forma de grupo e rede, já virtualmente contidas no funcionamento cerebral (daqui por diante chamaremos a estas estruturas apenas estruturasmentais).

Em seguida, Inhelder (1943/1963) toma por contraposição (no sentido lógico): se (não existe) estrutura mental, então (não existem) agrupamentos subjacentes à ação, ou seja: para que o modelo de Piaget seja verdadeiro é preciso demonstrar que se não há estrutura mental também não há agrupamentos subjacentes à ação e ao discurso.

Eis aí a idéia central de livro de Inhelder (1943/ 1963): estudar crianças com o diagnóstico de oligofrenia, logo com problemas na integração cortical, sem as estruturas mentais orgânicas adequadamente construídas, a fim de verificar se havia ou não subjacentea seus comportamentos e seus discursos (enquanto agiam sobre 0 mundo e verbalizavam sobre suas ações), os agrupamentos de classes e relações. A idéia genial de Bärbel foi a de procurar refutar o modelo piagetiano ao invés deconfirmálo. A confirmação das teorias, sempre preconizada pelo positivismo, teve suas dificuldades denunciadas por Popper (1935/1959) que nos mostrou as vantagens da refutabilidade. Bärbel utiliza-sedessa idéia ao mesmo tempo que ele e quase seguramente sem ter lido sua tese de doutorado, visto que, na época em que ela delineia a pesquisa, a tese de Popper (1935/1959) ainda estavainédita.

Inhelder (1943/ 1963) deixa explícito em sua obra que seu objetivo não era o de medir ou determinar qualitativamente um nível mental de ordem geral, englobando todas as funções psíquicas ou intelectuais, mas sim o de estudar uma função particular nos 
oligofrênicos, ou seja, o próprio raciocínio, isolando-o, na medida do possível, de outros mecanismos. Como imaginou ela ser possível estudar o raciocínio em si mesmo? Estudando a condição suficiente de sua existência: os agrupamentos subjacentes à ação e ao discurso (aquilo a que chamamos de raciocínio). Ela se pergunta: "o agrupamento determinando o equilíbrio e a gênese das noções racionais é ao mesmo tempo um princípio explicativo do desenvolvimento mental?" (Inhelder, 1943/1963, p. 47). Ela constatará inclusive que o agrupamento se constitui na lei imanente de sua estruturação progressiva. Uma de suas hipóteses foi a de que em um certo grau de profundidade de análise constata-se não, como se poderia esperar, um número indefinido de mecanismos operatórios, mas sim um número determinado de operações fundamentais e gerais que se repetem em toda construção intelectual e cujas etapas de desenvolvimento são as mesmas para todos os problemas mas com décalages e integrações variadas segundo os universos e os conteúdos. Ela dizia que identificar essas operações em um domínio bem circunscrito não significa perder-se na especialização em prejuízo do geral, mas simplesmente substituir, por uma anatomia mais fina de um certo órgão importante, 0 exame geral do sistema do qual esse órgão depende: tratase de encontrar o geral no particular, bem definido, em vez de procurá-lo na simples generalidade...

Inhelder (1943/1963) constata a ausência de agrupamentos subjacentes às ações dos oligofrênicos e também aos discursos que as dublam; e, ainda mais, que quanto mais o handicap da criança era profundo tanto mais as suas construções se afastavam dos prenúncios das classes e relações, portanto, dos agrupamentos. Ela nos explica queas provas piagetianasutilizadas para o diagnóstico do pensamento operatório permitem observar de perto como as estratégias da criança se organizam para se aproximarem de maneira cada vez mais rigorosa e sistemática das formas de organizacões complexas que se revelam isomorfas às das estruturas lógicas. Ela diz que se a hipótese feita por certos neurofisiólogos e ciberneticistas estiver certa, sugerindo que essas estruturas correspondem a potencialidades próprias às conexões cerebrais, seria interessante examinar detidamenteas deficiências ou desvios patológicos deste pensamento formal em ação.

Por outro lado, Inhelder (1943/ 1963) observa que se 0 pensamento operatório fosse essencialmente determinado pelos conteúdos sobre os quais o pensamento trabalha (conteúdos esses constituídos na experiência do dia-a-dia, pelas interações sociolingüísticas e escolares), deveríamos encontrar dentre os oligofrênicos de 13-14 anos, que durante 7 ou 8 anos tiveram uma escolarização especial, uma grande variedade de soluções em função dos problemas a eles propostos. Ao contrário, se nós admitirmos que o pensamento operatório não depende dos conteúdos assimilados, mas de uma atividade construtiva endógena, do próprio sujeito, nós deveríamos encontrar aqui (com os oligofrênicos) uma superposição aos momentos das realizações executadas pela criança normal. De fato, foi isso que encontrou. Diz ela:

É surpreendente verificar como as estruturas de raciocínio e os modos de justificação (dos oligofrênicos) são quase completamente passíveis de serem superpostos àqueles que nós conhecemos nas condutas de crianças menores, por ocasião da passagem de um pensamento préoperatório às manifestações as maiselementares do início da capacidade de operar. (Inhelder, 1943/1963, p. XXXIV)

O conjunto dos dados recolhidos fala em favor da hipótese segundo a qual a construção operatória, ainda que não independente das condutas sobre as quais ela se realiza, elabora-se, no entanto, segundo leis próprias. Lembramo-nos involuntariamente de Kant (1781/1950, p. 30): "o conhecimento começa na experiência, mas dela não deriva ...".

No que concerne à influência do "social", Inhelder (1943/1963) observa:

Nós teríamos nesse trabalho uma prova indireta de que a construção operatória não éunicamenteum produto cultural, elaborado em função dasinter-relações sociais, e de que suas leis de construção (cujo processo inverso nós vemos nos casos dedemência senil) parecem depender, demaneira mais ou menos estreita, das leis que regulam a integração cortical. (Inhelder, 1943/1963, p. XXV)

A juventude de Bärbel não a impede de entrever o alcance de sua pesquisa. Diz ela ao final de sua tese de doutorado, transformada em livro pela Delachaux \& Niestlé, em 1943:

Os resultados que nós temos a respeito do raciocínio dos jovens oligofrênicos podem, parece-nos, contribuir, por sua vez, para verificar a teoria da qual partimos; não só confirmando-a, mas enriquecendo-a com um ponto de vista novo. É pois sublinhando as interações possíveis entre uma concepção teórica e os resultados de sua comprovação no domínio do diagnóstico que nós gostaríamos de terminar essa obra. (Inhelder, 1943/1963, p. 278)

Inhelder (1943/1963) acrescenta ainda que, quando se utiliza um método que poderíamos chamar de "correlação negativa”, procurando estabelecer os sinais reveladores de uma inteligência normal pelo estudo dos 
fracassos relativos e insuficiências relativas, dentre os indivíduos que foram diagnosticados por outros métodos como portadores de oligofrenia, chegamos a identificar mais evidente e concretamente a interdependência e unidade profunda do desenvolvimento operatório e do funcionamento das estruturas mentais.

Nas conclusões de seu livro, Inhelder (1943/1963) retoma a hipótese fundamental de Piaget (1952):

Ora, o fato de haver encontrado nos sujeitos vítimas de toda sortede perturbações da inteligência e da conduta, diferindo uns dos outros pelo seu comportamento geral, a existência deuma construção operatória comum ecom as mesmas leis de integração, faz-nos tocar de perto a unidade profunda do lógico e do psicológico, no que concerne ao raciocínio. (Inhelder, 1943/1963, p. 278)

Ainda em suas conclusões encontramos algumas observações notáveis:

1) Sobre 0 agrupamento:

Esta construção porquefraca, não podendo jamais encontrar seu equilíbrio definitivo, parece colocar em evidência o fato de que a concretização dos agrupamentos é sinônimo do equilíbrio cognitivo próprio à idade mental de 12-13 anos (ou seja, do pensamento formal). (Inhelder, 1943/ 1963, p. 280)

2) Sobre a sua hipótese: "A criança normal se explica na criança com alguma patologia” (Inhelder, 1943/ 1963, p. 280)

3) Sobre os estágios e o meio ambiente:

Seédifícil atribuir às diferentes etapas da evolução cognitiva idades bem determinadas é porque, a ordem dos acontecimentos permanecendo a mesma, a velocidade da evolução pode variar de uma criança para outra, porque ela depende das influências do meio intelectual as quais podem estimular ou inibir a evolução do sujeito." (Inhelder, 1943/ 1963, p. 281)

4) Sobre a significação das etapas do desenvolvimento cognitivo:

De fato duas condições devem ser satisfeitas para que estejamos certos de estar diante de uma manifestação psicológica característica de uma determinada etapa: 1) quea aparição dessa manifestação seja preparada pelas condutas do estágio anterior; 2) que ela seja encontradano estágio posterior; (dito de outra maneira, que o novo encontre o velho) ... É necessário, pois, estar diante de uma real integração. (...) Não seconheceesse tipo deintegração a não ser em dois domínios: no da fisiologia e no da inteligência lógica; fora disso, os mecanismos de evolução mental nos escapam ainda ... Em resumo, os agrupamentos e suas regras parecem dirigir 0 desenvolvimento mental ... No entanto, mesmo no domínio privilegiado do raciocínio ondea implicação lógica confundese com a integração psicológica e onde observa-se uma correspondência real entreos estágios operatórios e os níveis mentais, subsistem certas dificuldades de traduzir os primeiros na linguagem dos segundos. (Inhelder, 1943/ 1963, p. 283)

Em Lediagnostiquedu raisonnement chez les débilesmentaux, Bärbel Inhelder pôde mostrar: 1) que os agrupamentos estão ligados a uma organização e a uma atividade endógena e que dependem da integração cortical; 2) que 0 agrupamento é o coroamento de um processo evolutivo; 3) que o agrupamento explica esse processo e, além disso, é a expressão de suas leis; 4) que a seqüência em que as etapas do processo cognitivo são construídas é necessária.

Nossas pesquisas pessoais e atuais têm mostrado que uma inversão dessa seqüência determina transtornos de conduta e emoção, mas aqui estamos apenas para falar da genial pesquisadora Bärbel Inhelder, cujas idéias as mais fecundas surgiram-lhe antes dos trinta anos e cujo reconhecimento no Brasil émuito pequeno.

\section{Referências}

Inhelder, B. (1963). Le diagnostic du raisonnement chez les débiles mentaux. Neuchâtel: Delachaux \& Niestlé. (Original publicado em 1943)

Kant, I. (1950). Critique de la raison pure Paris: PUF. (Original publicado em 1781)

Popper, K. (1959). The logic of scientific discovery. New York: Basic Books Inc. (Original publicado em 1935)

Piaget, J. (1952). La logistique axiomatique ou pure, la logistique opératoire ou psychologique et les réalités auxquelles elles correspondent. Methodos,13, 72-84.

Piaget, J. (1959). Les modèles abstraits sont-ils opposés aux interpretations psycho-physiologiques dans l'explication en psychologie? Bulletin de Psychologie, 1969, 7-13.
Recebido: 19/11/2001

Revisado: 08/03/2002

Aœite Final: 22/05/2002

Zelia Ramozzi-Chiarottino éProfessora titular da Universidadede São Paulo. 